\section{Anthocyanin, Carotenoid Content, and Antioxidant Values in Native South American Potato Cultivars}

\author{
Charles R. Brown ${ }^{1}$ \\ USDA/ARS, Horticulture L/A, 24106 N. Bunn Road, Prosser, WA 99350
}

David Culley

Batelle Pacific Northwest Laboratories, Richland, WA 99352

Meredith Bonierbale and Walter Amorós
Department of Genetic Resources and Breeding, International Potato
Center, Lima, Peru

Additional index words. ORAC, pigments, germplasm, specialty potatoes, Solanum chaucha, Solanum tuberosum, Group Goniocalyx, Group Phureja, Group Stenotomum

\begin{abstract}
Tubers of 38 native potato cultivars of different taxonomic groups from South America were analyzed to determine the total anthocyanins, total carotenoids, and antioxidant values. Total anthocyanin ranged from zero to $23 \mathrm{mg}$ cyanidin equivalents/ $100 \mathrm{~g}$ fresh weight (FW). Total carotenoid ranged from 38 to $2020 \mu \mathrm{g}$ zeaxanthin equivalents/100 g FW. Oxygen radical absorbance capacity (ORAC) was measured for the anthocyanin (hydrophilic) and carotenoid (lipophilic) extracts. The hydrophilic ORAC ranged from 333 to $1408 \mu \mathrm{M}$ Trolox equivalents/100 $\mathrm{g}$ FW. The lipophilic ORAC ranged from 4.7 to $30 \mathrm{nM} \alpha$-tocopherol equivalents $/ 100 \mathrm{~g} \mathrm{FW}$. The cultivars consisted of 23 diploids, seven triploids, and eight tetraploids. Total carotenoids was negatively correlated with total anthocyanins. Total anthocyanins was correlated with hydrophilic ORAC. Among clones with less than $2 \mathrm{mg}$ cyanidin equivalents/100 $\mathrm{g}$ FW, total carotenoid and lipophilic ORAC were correlated, but this was not true for analysis of all 38 clones. Although total anthocyanins or hydrophilic ORAC values reported here were not outside of the ranges found in North American and other breeding materials, total carotenoids and lipophilic ORACs are higher than previously reported, suggesting that native cultivars of South America with high levels of total carotenoids and high lipophilic ORAC are a unique germplasm source for introgression of these traits into specific potato cultivars outside the center of origin.
\end{abstract}

Potato (Solanum tuberosum L.) was domesticated in the Andes Mountains of South America (Spooner et al., 2006). At the time of European contact, potato was and continues to be a staple of the numerous societies living in the Andes. Potato was first introduced to Europe at the end of the 16th century and then experienced worldwide distribution over several centuries (Hawkes, 1992). Over time, skin and flesh color outside the center of origin have been reduced to a few types that represent a subset of the extant variation in native Andean cultivars. These colors are primarily red and blue anthocyanins that are present in skin or flesh to varying degrees and yellow to orange carotenoids in the flesh that display a broad variation in content. Although native cultivars have been used extensively for introduction of disease and pest resistance traits into long-day adapted cultivars, they have not been accessed with the purpose of introgressing enhanced phytonutrient content until recently (Brown,

Received for publication 28 Feb. 2007. Accepted for publication 19 June 2007.

${ }^{1}$ To whom reprint requests should be addressed; e-mail cbrown@pars.ars.usda.gov.
2005). Cultivated potato in South America is represented by diploid, triploid, tetraploid, and pentaploid cultivars. Tetraploid cultivars (Group Andigena) comprise the greatest number of accessions and have the widest geographic distribution (Glendinning, 1983; Hawkes, 1990).

Cultivated potatoes contain varying amounts of anthocyanins and carotenoids in their tuber skin and flesh (Gross, 1991; Mazza and Miniati, 1993). Potato anthocyanins include acylated glucosides of several aglycons: pelargonidin, petunidin, malvidin, and peonidin (Brown et al., 2003; Fossen and Andersen, 2000; Fossen et al., 2003; Rodriguez-Saona et al., 1998). The carotenoids are xanthophylls, which are not provitamin A carotenoids, and, interestingly, only traces of beta-carotene, which can be converted to vitamin A, are found. Therefore, potatoes are a good source of xanthophylls, components of the human retina, but are deficient in provitamin A compounds. Outside the center of origin of cultivated potato in the Andes of South America, it is rare to find cultivars with anthocyanin pigments conferring red or purple flesh. However, much of the world's production is dominated by yellow-fleshed potatoes, which have higher total carotenoids than the white-fleshed cultivars of North America and Great Britain. Genetic control of presence or absence of anthocyanins is monogenic, although the distribution of anthocyanin in pigmented flesh may be under complex genetic control (Brown et al., 2003; De Jong, 1991). White versus yellow flesh is thought to be under single gene control with gene maps agreeing on the placement of this yellow flesh factor $(Y / y)$ on chromosome 3 (Bonierbale et al., 1988; Gebhardt et al., 1989). White- and yellow-fleshed potatoes have similar composition of carotenoids, with the yellow color of the latter group attributable to higher concentrations (Brown et al., 1993; Gross, 1991). The different types of xanthophylls show variable concentrations in various potato genotypes with lutein predominating and varying amounts of zeaxanthin, violaxanthin, and others reported (Brown et al., 1993; Iwanzik et al., 1983; Lu et al., 2001; Nesterenko and Sink, 2003). The greatest levels of total carotenoids are from the potato cultivars of the Andes referred to as 'Papa Amarilla' (Yellow Potato) and breeding materials derived from this source. They are composed of diploid cultivated potatoes $S$. tuberosum L. in the Groups Phureja, Stenotomum, and Goniocalyx (Spooner and Hetterscheid, 2006).

Brown et al. (1993) reported wide variation in segregating genotypes derived from Papa Amarilla germplasm, with some samples exceeding $2000 \mu \mathrm{g}$ zeaxanthin equivalents/100 g fresh weight (FW). Several other studies have reported similar high levels (Brown et al., 2005; Lu et al., 2001). In a report by Brown et al. (1993), the existence of a so-called orange allele, $O r$, was postulated at the $Y / y$ locus to explain higher levels of carotenoids. Breeding efforts directed at producing commercially viable cultivars with higher levels of anthocyanin and carotenoid for health benefits of their antioxidant properties have recently been undertaken by regional programs (Brown, 2005). The purpose of this study was to analyze native South American cultivars and compare them with modern breeding lines and cultivars in relation to total anthocyanins, total carotenoids, and associated antioxidant values. This information may guide future breeding work to the extent that introgressing traits from South American germplasm may assist in enhancing these traits.

\section{Materials and Methods}

Genetic materials. The genotypes chosen for this study consisted of 38 cultivars selected for coloration of skin and flesh combined with high dry matter. Table 1 presents their nomenclature, chromosome number, taxonomic identity, and country of origin. Tubers were produced from plants derived from in vitro stock transplanted to pots and grown in the greenhouse at the Huancayo facility of the International Potato Center, Peru (at $3330 \mathrm{~m}$ above sea level). Tubers from 20 different pots per genotype were bulked and two sets of two tubers of each 
Table 1. List of South American cultivar names (if known), International Potato Center (CIP) accession numbers, country of origin, chromosome number $(2 \mathrm{n}=)$, and group designation within Solanum tuberosum.

\begin{tabular}{|c|c|c|c|c|}
\hline Cultivar name & CIP number & Origin & Chromosome number & Group \\
\hline Amarilla Tumbay & 701862 & Per & 24 & gon \\
\hline Calhua Rosada & 701165 & Per & 24 & stn \\
\hline Capacho Azul & 703698 & Per & 24 & stn \\
\hline Caramelo & 701676 & Per & 24 & $\operatorname{stn}$ \\
\hline Cashpadana Amarilla & 703352 & Per & 24 & gon \\
\hline Ceccorani & 703287 & Per & 24 & $\operatorname{stn}$ \\
\hline Challina & 703488 & Per & 48 & $\operatorname{adg}$ \\
\hline Chaucha Amarilla & 703308 & Per & 24 & phu \\
\hline Chiimbina Colorada & 701013 & Per & 36 & cha \\
\hline Chujo Papa & 704193 & Per & 48 & adg \\
\hline Cuchipa Ismaynin & 700313 & Per & 24 & $\operatorname{stn}$ \\
\hline Garhuash Pashon & 702961 & Per & 24 & gon \\
\hline Huataqui & 701014 & Per & 36 & juz \\
\hline Ishco Puro & 701266 & Per & 24 & stn \\
\hline Muro Shocco & 701273 & Per & 48 & $\operatorname{adg}$ \\
\hline Negra & 703789 & Per & 48 & adg \\
\hline No name & 702610 & Bol & 24 & $\operatorname{stn}$ \\
\hline No name & 703274 & Per & 24 & phu \\
\hline No name & 703279 & Per & 24 & gon \\
\hline No name & 703280 & Per & 24 & gon \\
\hline No name & 703315 & Per & 24 & gon \\
\hline Paccocha & 703300 & Per & 36 & cha \\
\hline Papa Chonca & 703606 & Chl & 48 & cha \\
\hline Puca Corika & 700739 & Per & 36 & cha \\
\hline Puca Huayro & 701524 & Per & 36 & cha \\
\hline Puca Pishgush & 703168 & Per & 24 & gon \\
\hline Puca Quitish & 703264 & Per & 48 & adg \\
\hline Puca Trombos & 702915 & Per & 48 & adg \\
\hline Puka Suytu & 704355 & Per & 48 & adg \\
\hline Rosca & 703291 & $\mathrm{Col}$ & 24 & phu \\
\hline Tarmeña & 701675 & Per & 36 & cha \\
\hline Tumiri & 701568 & Per & 36 & cha \\
\hline Yana Pituwaya & 703286 & Bol & 24 & stn \\
\hline Yana Ppoccoya & 703288 & Per & 24 & $\operatorname{stn}$ \\
\hline Yana Sucre & 703197 & Per & 24 & stn \\
\hline Yana Turuna & 703314 & Per & 24 & $\operatorname{stn}$ \\
\hline Yema de Huevo & 704218 & $\mathrm{Col}$ & 24 & phu \\
\hline Zapallo & 703244 & Bol & 24 & gon \\
\hline
\end{tabular}

Col = Colombia; Per = Peru; Bol = Bolivia Chl = Chile $;$ adg = Andigena $;$ phu $=$ Phureja $;$ gon $=$ Goniocalyx $; \mathrm{stn}=$ Stenotomum $;$ cha $=$ Chaucha $;$ juz $=$ Solanum $\times$ juzepzukii .

genotype were selected randomly to form two replications. Tubers were diced with skin into small cubes ( $1-\mathrm{cm}$ square), frozen immediately in liquid nitrogen, and maintained at $-80{ }^{\circ} \mathrm{C}$ in tightly sealed Nalgene bottles. Extraction proceeded from the frozen tuber pieces.

Anthocyanin (hydrophilic) extraction and quantification. Anthocyanin extraction followed the protocols outlined in Durst and Wrolstad (2001) as modified by Brown et al. (2003, 2005). Potato tissue was blended and weighed out as $10 \mathrm{~g}$ of frozen powder to start the extraction. Monomeric anthocyanin content was determined using the $\mathrm{pH}$ differential method (Giusti and Wrolstad, 2001). Pigment content was calculated as cyanidin-3-glucoside equivalents using an extinction coefficient of $26,900 \mathrm{~L} \cdot \mathrm{cm}^{-1} \cdot \mathrm{mol}^{-1}$ and molecular weight (MW) of $449.2 \mathrm{~g} \cdot \mathrm{mol}^{-1}$.

Carotenoid (lipophilic) extraction and quantification. Total carotenoids were extracted and quantified using the methods reported in Brown et al. (2005), which contained minor modifications of procedures presented in van Breemen (2001). Frozen tissue was pulverized in a blender and measured out as $250 \mathrm{mg}$ of frozen powder. Carotenoids were extracted in a chloroform: modate its performance in a polar solvent with an adjuvant to solubilize the carotenoids. The method used was a modification of the procedure of Huang et al. (2002) reported in Brown et al. (2005). Antioxidant values were reported as nanoMoles of $\alpha$-tocopherol equivalents/100 g FW.

Statistical analysis. Analysis of variance following a randomized complete block design and Duncan's multiple range test was applied to the means (Steel and Torrie, 1980). Correlations were calculated using Microsoft Excel (Microsoft, Redmond, WA). All genotypes were subjected as a single group to analysis of variance by SAS (version 9.1.3, PROC REG; Cary, NC) applying a general linear model. The effect of ploidy was tested by orthogonal comparisons. All analyses were based on two replications.

\section{Results and Discussion}

Total anthocyanins ranged from 0 to $23 \mathrm{mg}$ cyanidin equivalents/100 g FW in this group (Table 2). Total carotenoids ranged from 38 to $2020 \mu \mathrm{g} / 100 \mathrm{~g} \mathrm{FW}$. The genotype 703280 had low total anthocyanins in the flesh but the highest total carotenoids level of all genotypes. The four highest carotenoid levels were found in one diploid and three triploids (703280, 'Tarmeña', 'Puca Corika', and 'Paccocha'). The hydrophilic ORACs ranged between 333 and $1408 \mu \mathrm{M}$ Trolox equivalents $/ 100 \mathrm{~g} \mathrm{FW}$. There was a significant positive correlation of total anthocyanins with hydrophilic ORAC $(r=0.51, P<$ $0.05, R^{2}=0.26$ ). Lipophilic ORACs ranged between 4.7 and $30 \mathrm{nM} \alpha$-tocopherol equivalents/100 g FW. There was no correlation between carotenoid content and lipophilic ORAC in the 38 clones as a whole, but when considering cultivars with less than $2 \mathrm{mg}$ of total cyanidin equivalents $/ 100 \mathrm{~g} \mathrm{FW}$, total carotenoids and lipophilic ORACs were correlated $\left(r=0.48, P<0.05, R^{2}=0.23\right)$. The relatively low $\mathrm{R}^{2}$ values indicated that factors other than carotenoids and anthocyanins also contribute substantially to antioxidant values. Total carotenoids and total anthocyanins were negatively correlated $(r=-0.41, P<$ $0.05, R^{2}=0.17$ ).

The cultivar 'Huataqui' is a member of Solanum $\times$ jucepzukii (JUZ.), a highly frosttolerant bitter potato adapted to cultivation at high elevations where risk of midseason frosts is high (Huanco, 1991). It is notable for having no anthocyanin and the second lowest total carotenoids of all cultivars tested.

When the effect of ploidy was examined in Table 3, it is apparent that total anthocyanins is higher with higher ploidy. However, hydrophilic ORAC did not differ among ploidies. Diploids and triploids had greater total carotenoids than tetraploids, and diploids had greater lipophilic ORAC values than tetraploids. Because these clones were selected on the basis of extremes in pigmentation, these differences should not be extrapolated to the thousands of native cultivars 
Table 2. Total anthocyanins, hydrophilic oxygen radical absorption capacity (ORAC), total carotenoids, and lipophilic ORAC of South American potato cultivars.

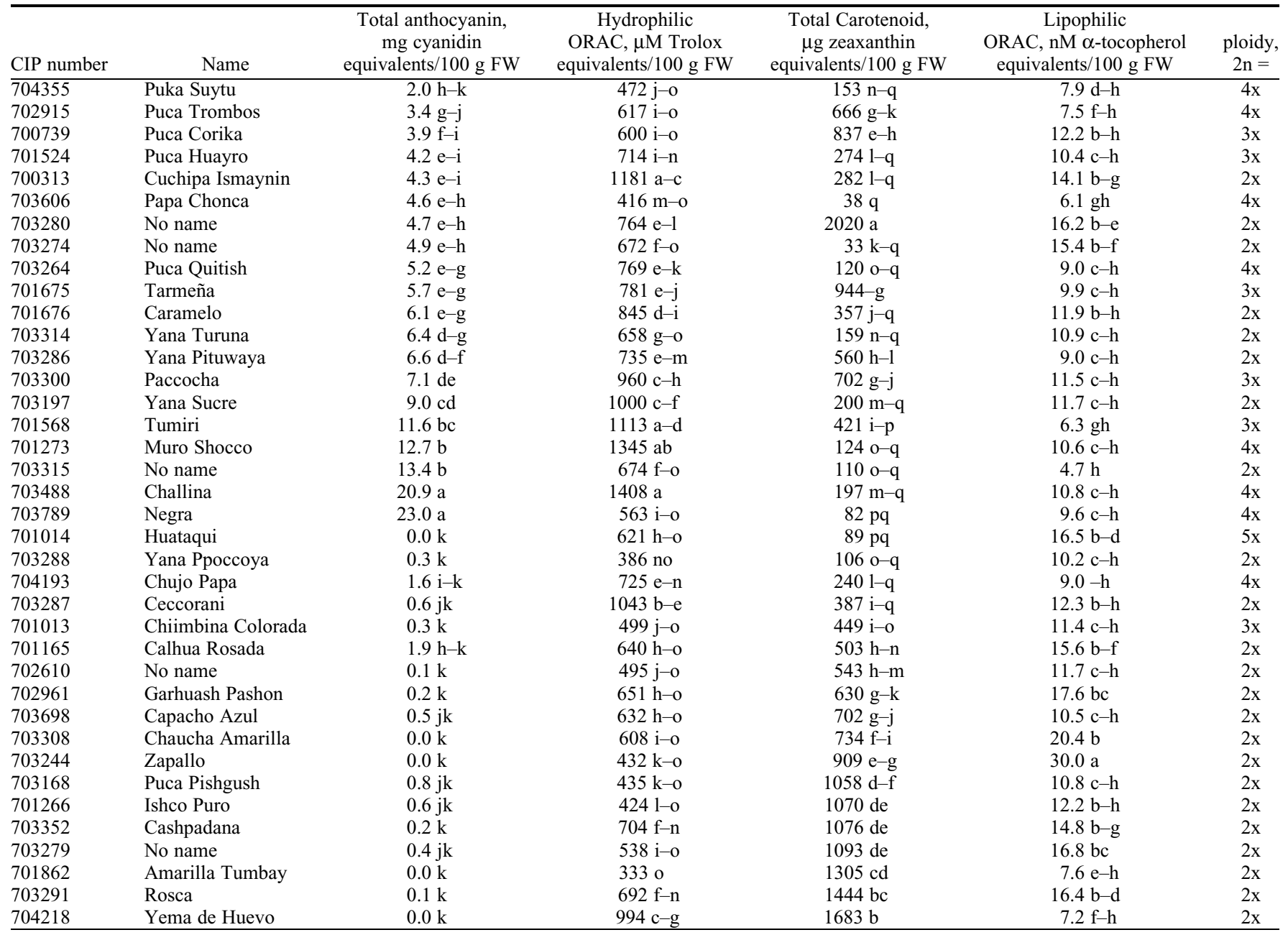

Means not sharing a letter are significantly different at $P<0.05$ level using Duncan's multiple range test.

Table 3. Comparison of means of three ploidy levels, diploid, triploid, and tetraploid, for total anthocyanins, hydrophilic oxygen radical absorption capacity (ORAC), total carotenoids, and lipophilic ORAC.

\begin{tabular}{lcccc}
\hline & $\begin{array}{c}\text { Total anthocyanin } \\
\text { mg cyanidin } \\
\text { equivalents/100 g FW }\end{array}$ & $\begin{array}{c}\text { Hydrophilic-ORAC } \mu \mathrm{M} \\
\text { Trolox equivalents/100g FW }\end{array}$ & $\begin{array}{c}\text { Total carotenoid } \mu \mathrm{g} \\
\text { zeaxanthin } \\
\text { equivalents/100 g FW }\end{array}$ & $\begin{array}{c}\text { Lipophilic-ORAC } \\
\text { nM } \alpha \text {-tocopherol } \\
\text { equivalents/100 g FW }\end{array}$ \\
Ploidy & $2.6 \mathrm{a}$ & $675 \mathrm{a}$ & $751 \mathrm{a}$ & \\
Diploid $(\mathrm{N}=23)$ & $5.5 \mathrm{~b}$ & $778 \mathrm{a}$ & $604 \mathrm{a}$ & $13.4 \mathrm{a}$ \\
Triploid $(\mathrm{N}=7)$ & $9.2 \mathrm{c}$ & $789 \mathrm{a}$ & $202 \mathrm{~b}$ & $10.3 \mathrm{ab}$ \\
Tetraploid $(\mathrm{N}=8)$ & & & $8.8 \mathrm{~b}$ \\
\hline
\end{tabular}

Means tested by orthogonal comparisons. Those not sharing a letter are significantly different at $P<0.05$.

in the World Collection at the International Potato Center. 'Papa Amarilla', a broad category of potato cultivars in the Andes, embraces both diploid germplasm and Solanum chaucha, which is triploid $(2 \mathrm{n}=36)$.

On comparison with recently published literature of germplasm in the United States, equivalent and higher total anthocyanin levels can be found. Brown et al. (2003, 2005) reported total anthocyanin values ranging between 15 and $38 \mathrm{mg} / 100 \mathrm{~g} \mathrm{FW}$. Similarly, high levels of total anthocyanin exceeding those values reported here were described by Lewis et al. (1998) in New Zealand. There appear to be in North America and New Zealand breeding materials or named cultivars with levels of anthocyanin surpassing the genotypes in this study. This is not the case when total carotenoids are considered.
Levels of total carotenoids in tuber flesh of cultivars and unusual breeding materials are generally in the range of 50 to $400 \mu \mathrm{g}$ zeaxanthin equivalents/100 g FW. Levels exceeding this are derived very clearly from diploid germplasm obtained from Andean locations in South America (Andre et al., 2007; Brown et al., 1993, 2005; Campos et al., 2006; Lu et al., 2001). The high levels of total carotenoids described in these publications are from South American cultivars or breeding materials adapted to long-day latitudes with South American ancestors in the Group Phureja, but they remain experimental in nature. The high total carotenoids trait (i.e., greater than $1000 \mu \mathrm{g}$ zeaxanthin equivalents/100 g FW) of South American 'Papa Amarilla' cultivars is still not introgressed into long-day adapted commercial cultivars grown outside of South America. They constitute a unique and valuable resource for breeding. The highest level of hydrophilic ORAC in the cultivar 'Challina' is close to the highest level reported in Brown

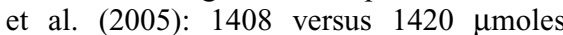
Trolox equivalents/100 g FW in 'Challina' and NDOP5847-1 (in citation), respectively. The lipophilic ORAC values presented in Table 2 exceed the highest value of 15 nmoles $\alpha$-tocopherol equivalents/100 g FW reported by Brown et al. (2005). Cultivars 'Zapallo' and 'Chaucha Amarilla' were measured at 30 and 20 nmoles $\alpha$-tocopherol equivalents/100 g FW, respectively. Therefore, these examples of Andean germplasm appear to be notable for higher lipophilic ORACs than can be found in North American and New Zealand cultivars. The combination 
of high total carotenoids and high lipophilic ORAC is, therefore, a unique phytonutrient trait combination available in particular South American diploid or triploid cultivars.

\section{Literature Cited}

Andre, C.M., M. Ghislain, P. Bertin, M. Oufir, M. del Rosario Herrera, L. Hoffmann, J.-F. Hausman, Y. Larondelle, and D. Evers. 2007. Andean potato cultivars (Solanum tuberosum L.) as a source of antioxidant and mineral micronutrients. J. Agr. Food Chem. 55:366-378.

Bonierbale, M.W., R.L. Plaisted, and S.D. Tanksley. 1988. RFLP maps based on a common set of clones reveal modes of chromosomal evolution in potato and tomato. Genetics 120:10951103.

Brown, C.R. 2005. Antioxidants in potato. Amer. J. Potato Res. 62:163-172.

Brown, C.R., D. Culley, C.-P. Yang, R. Durst, and R. Wrolstad. 2005. Variation of anthocyanin and carotenoid contents and associated antioxidant values in potato breeding lines. J. Amer. Soc. Hort. Sci. 130:174-180.

Brown, C.R., C.G. Edwards, C.-P. Yang, and B.B. Dean. 1993. Orange flesh trait in potato: Inheritance and carotenoid content. J. Amer. Soc. Hort. Sci. 118:145-150.

Brown, C.R., R. Wrolstad, R. Durst, C.-P. Yang, and B. Clevidence. 2003. Breeding studies in potatoes containing high concentrations of anthocyanins. Amer. J. Potato Res. 80:241-250.

Campos, D., G. Noratto, R. Chirinos, C. Arbizu, W. Roca, and L. Cisneros-Zevallos. 2006. Antioxidant capacity and secondary metabolites in four species of Andean tuber crops: Native potato (Solanum sp.), mashua (Tropeaolum tuberosum Ruiz \& Pavon), oca (Oxalis tuberosa Molina) and ulluco (Ullucus tuberosus Caldas). J. Sci. Food Agr. 86:1481-1488.

Cao, G., H.M.M. Alessio, and R.G. Cutler. 1993. Oxygen-radical absorbance capacity for antioxidants. Free Radic. Biol. Med. 14:303-311.

Cao, G., C.P. Verdon, A.H.B. Wu, H. Wang, and R.L. Prior. 1995. Automated oxygen radical absorbance capacity assay using the COBAS FARA II. Clin. Chem. 41:1738-1744.

De Jong, H. 1991. Inheritance of anthocyanin pigmentation in the cultivated potato: A critical review. Amer. Potato J. 68:585-593.

Durst, R.W. and R. Wrolstad. 2001. Separation and characterization of anthocyanins by HPLC, $p$. 1.3.1-1.3.13. In: R.E. Wrolstad (ed.). Current protocols in food analytical chemistry. Wiley, New York.

Fossen, T. and Ø.M. Andersen. 2000. Anthocyanins from tubers and shoots of the purple potato, Solanum tuberosum. J. Hort. Sci. Biotechnol. 75:360-363.

Fossen, T., D.O. Øvstedal, R. Slimestad, and Ø.M. Andersen. 2003. Anthocyanins from a Norwegian potato cultivar. Food Chem. 81:433-437.

Gebhardt, C., E. Ritter, T. Debener, U. Schnachtschabel, B. Walkemeier, H. Uhrig, and F. Salamini. 1989. RFLP analysis and linkage mapping in Solanum tuberosum. Theor. Appl. Genet. 78:65-75.

Giusti, M.M. and R.E. Wrolstad. 2001. Anthocyanins: Characterization and measurement with UV-visible spectroscopy, p. F1.2.1-1.2.13. In: R.E. Wrolstad (ed.). Current protocols in food analytical chemistry. Wiley, New York.

Glendinning, D.R. 1983. Potato introductions and breeding up to the early $20^{\text {th }}$ century. New Phytol. 94:479-505.

Gross, J. 1991. Pigments in vegetables: Chlorophylls and carotenoids. Van Nostrand Reinhold, New York.

Hawkes, J.G. 1990. The potato: Evolution, biodiversity and genetic resources. Bellhaven Press, London.

Hawkes, J.G. 1992. History of potato, p. 1-12. In: P. Harris (ed.). The potato crop. Chapman and Hall, London.

Huanco, V. 1991. Potencial de las papas amargas en el altiplano de Puno, Peru, p. 25-26. In: J. Rea and J.J. Vacher (eds.). La papa amarga. 1st Roundtable: Peru-Bolivia. La Paz. May, 7-8, 1991. ORSTOM, La Paz, Bolivia.

Huang, D.B., M. Ou, J.A. Hampsch-Woodill, J.A Flanagan, and E.K. Deemer. 2002. Development and validation of oxygen radical absor- bance capacity assay for lipophilic antioxidants using randomly methylated beta-cyclodextrin as the solubility enhancer. J. Agr. Food Chem. 50:1815-1821.

Iwanzik, W., M. Tevini, R. Stute, and R. Hilbert. 1983. Carotinoidgehalt und Zusammensetzung verschiedener deutscher Kartoffelsorten und deren Bedeutung fur die Fleischfarbe der Knolle. Potato Res. 26:149-162.

Lewis, C.E., J.R.L. Walker, J.E. Lancaster, and K.H. Sutton. 1998. Determination of anthocyanins, flavonoids and phenolic acids in potatoes. I: Coloured cultivars of Solanum tuberosum L. J. Sci. Food Agr. 77:45-57.

Lu, W.H., K. Haynes, E. Wiley, and B. Clevidence. 2001. Carotenoid content and color in diploid potatoes. J. Amer. Soc. Hort. Sci. 126: 722-726.

Mazza, G. and E. Miniati. 1993. Anthocyanins in fruits, vegetables and grains. CRC Press, Boca Raton, FL.

Nesterenko, S. and K.C. Sink. 2003. Carotenoid profiles of potato breeding lines and selected cultivars. HortScience 38:1173-1177.

Rodriguez-Saona, L.E., M.M. Giusti, and R.E. Wrolstad. 1998. Anthocyanin pigment composition of red-flesh potatoes. J. Food Sci. 63:458-465.

Spooner, D.M. and W.L.A. Hetterscheid. 2006. Origins, evolution and group classification of cultivated potatoes, p. 285-307. In: T.J. Motley, N. Zerega, and H. Cross (eds.) Darwin's harvest: New approaches to the origins, evolution, and conservation of crops. Columbia Univ. Press, New York.

Spooner, D.M., K. McLean, G. Ramsay, R. Waugh, and G.J. Bryan. 2006. A single domestication for potato based on multilocus amplified fragment length polymorphism genotyping. Proc. Natl. Acad. Sci. USA 102:14694-14699.

Steel, R.G.D. and J.H. Torrie. 1980. Principles and procedures of statistics: A biometrical approach. McGraw-Hill, New York.

van Breemen, R.B. 2001. Carotenoids, p. F2.1.1F2.4.6. In: R.E. Wrolstad (ed.). Current protocols in food analytical chemistry. Wiley, New York. 